\section{To lead by example}

Even though the journal is well into the volume year, I can't help but feel like this is still a beginning: partially because those of us who are slaves to the academic calendar are about the commence another Fall and partially due to my still being in the "honeymoon" period with College E Research Libraries. As such, I read the submissions as they come in, intrigued by the research questions and arguments, study the evaluative comments from reviewers, provide guidance to authors, and consider how each paper contributes to the literature and the profession. Each article provides a unique perspective relevant to the focus of the journal, and I learn something from every single one.

Once they come together into an issue, it is amazing to see the breadth of topics and the way in which each paper engages with academic, professional, and societal concerns. C\&RL is truly representative of the larger conversations happening in academic librarianship and in higher education. It is critical that scholarly literature initiate or contribute to the dialogue in a way that models the diverse values and priorities of academic libraries and ACRL. The slate for this issue of the journal does just that, addressing core values in libraries such as open access, the value of academic libraries and faculty status, as well as issues facings colleges and universities at large. Galbraith and his colleagues contribute to the ongoing debate about the status of tenure with a study of perceived benefits and advantages. Looking at the ongoing competition between library resources versus Google, a longitudinal study by Perruso looks at the evolving research behavior of undergraduate students. Also addressing resource access and usage, Musser and Coopey examine the "Impact of a Discovery System on Interlibrary Loan." Cain, et al. look to the future with an analysis of forecasted service trends while a study by Murray and his coauthors finds a correlation between library use and student retention. Open

Wendi Kaspar is C\&RL editor and policy sciences librarian at the Texas A\&M University Policy Sciences and Economics Library,email:warant@library.tamu.edu access, not surprisingly, is the subject of two studies, both examining adoption in organizations and providing an interesting juxtaposition between ALA and a top-tier university. Hall's study specifically asks the question if the association's journals are "Leading by Example?" with a very intentional approach. Speaking for this journal, it is certainly our primary mission.

- Samantha Teplitzky and Margaret Phillips. "Evaluating the Impact of Open Access at Berkeley: Results from the 2015 Survey of Berkeley Research Impact Initiative (BRII) Funding Recipients." Abstract: The Berkeley Research Impact Initiative (BRII) was one of the first campus-based open access (OA) funds to be established in North America and one of the most active, distributing more than $\$ 244,000$ to support University of California (UC) Berkeley authors. In April 2015, we conducted a qualitative study of 138 individuals who had received BRII funding to survey their opinions about the benefits and funding of OA. Most respondents believe their articles had a greater impact as OA, expect to tap multiple sources to fund open access fees, and support the UC Open Access Policy and its goal of making research public and accessible. Results of the survey and a discussion of their impact on the BRII program follow.

- Quinn Galbraith, Melissa Garrison, and Whitney Hales. "Perceptions of Faculty Status among Academic Librarians." Abstract: This study measures the opinions of Association of Research Libraries librarians concerning the benefits and disadvantages of faculty status in academic librarianship. Average responses from faculty and nonfaculty librarians, as well as from tenured and tenure-track librarians, are analyzed to determine the general perceptions of each group. Overall, faculty librarians reported more positive perceptions of faculty status than nonfaculty librarians. Tenured librarians generally reported more positive perceptions than tenure-track librarians. Despite the differences in opinion, these results offer insight into the potential benefits and disadvantages of faculty status in academic librarianship and suggest that faculty status improves relation- 
ships with teaching faculty, even if status alone cannot make them full peers.

- Timothy J. Cain, Fern M. Cheek, Jeremy Kupsco, Lynda J. Hartel, and Anna Getselman. "Health Sciences Libraries Forecasting Information Service Trends for Researchers: Models Applicable to All Academic Libraries." Abstract: To better understand the value of current information services and to forecast the evolving information and data management needs of researchers, a study was conducted at two research-intensive universities. The methodology and planning framework applied by health science librarians at Emory University and The Ohio State University focused on identifying the need for new or retooled information services supporting health and biomedical researchers and their increasing use of digital resources. The lessons learned and outcomes described herein are informing the development and implementation of new information service models and can help forecast changing user needs across the broader library community.

- Carol Perruso. "Undergraduates' Use of Google vs. Library Resources: A Four-Year Cohort Study." Abstract: This longitudinal study at a large public university surveyed students of the 2008 freshmen cohort over four years about their use of websites and library resources for their research papers. The three goals of the study were to track changes in reported research behavior over time, to see if students' reported source choices were associated with librarian instruction and/or if they were associated with instructors' source requirements. The study found that, as students matured, they used library resources more frequently. Librarian instruction and faculty source requirements also were associated with increased use of library resources.

- Adam Murray, Ashley Ireland, and Jana Hackathorn. "The Value of Academic Libraries: Library Services as a Predictor of Student Retention." Abstract: This study examined the predictive relationship between library use by individual students and their retention status in university settings. The methodology builds on a small number of previous studies to examine library use at the individual level to determine if use of specific library services is predictive of retention for freshmen and sophomores. Binary logistic regression yielded results that indicate a strong positive predictive relationship between library use of any kind with both freshmen and sophomore retention. These results suggest that academic libraries add value to institutional retention efforts.

- Linda R. Musser and Barbara M. Coopey. "Impact of a Discovery System on Interlibrary Loan." Abstract: Web-scale discovery services such as Summon (Serial Solutions), WorldCat Local (OCLC), EDS (EBSCO), and Primo (Ex Libris) are often touted as a single search solution to connect users to library-owned and -licensed content, improving discoverability and retrieval of resources. Assessing how well these systems achieve this goal can be challenging, however. This article describes the use of interlibrary loan borrowing request data as a means to evaluate whether the Summon discovery system was achieving its goal of improving retrieval. Four years following implementation of the discovery system, there was a 22 percent decrease in interlibrary loan borrowing requests. Requests by undergraduates dropped at a higher rate than faculty, staff, and graduate students. Undergraduate requests for articles dropped more than requests for loans. Two years' postimplementation of the discovery system, the number of interlibrary loan borrowing requests by undergraduates for locally owned or licensed materials dropped by 57 percent, freeing up interlibrary loan staff to expand services into new areas. This study indicates that implementation of a discovery system can lead to a reduction in interlibrary loan borrowing.

- Nathan Hall, Sara Arnold-Garza, Regina Gong, and Yasmeen Shorish. "Leading by Example? ALA Division Publications, Open Access, and Sustainability." Abstract: This investigation explores scholarly communication business models in ALA division peer-reviewed academic journals. Previous studies reveal the numerous issues organizations and publishers face in the academic publishing environment. Through an analysis of documented procedures, policies, and finances of five ALA division journals, we compare business and access models. We conclude that some ALA divisions prioritize the costs associated with changing business models, including hard-to-estimate costs such as the labor of volunteers. For other divisions, the financial aspects are less important than maintaining core values, such as those defined in ALA's Core Values in Librarianship. $\boldsymbol{z}$ 